\title{
METHODOLOGY FOR ASSESSING TRANSPORT CONNECTIONS ON THE INTEGRATED TRANSPORT NETWORK
}

\begin{abstract}
The periodic line transport expresses an integrated periodic timetable, which is also a periodical liner form of surveillance and network interconnection. An important factor is to reduce the interchange times in selected areas, or transport hubs. The aim is to minimise the total transit time of a passenger from point A to point $B$. The cornerstone of transport services is to provide travel opportunities by creating links and connections. Often, after the introduction of the new timetable and a discussion of whether it is better or worse, each approach is evaluated in a subjective manner. The authors solved some problems of rail passenger quality services. At present, there is no methodology for assessing train timetables from the transportation point of view as a whole. We evaluate specific trains and connections in the stations only, but not the quality of the connection from point $A$ to point $B$.
\end{abstract}

Keywords: Relation, Lill's model, integrated transport network, quality.

\section{Dependence of integrated transport network}

A transport network is a set of hubs and connecting road sections. On the transport network are moving, entering and then outputting physical objects (e.g. passenger trains, wagon load, etc.). A mathematical model of the network may have a final graph of a finite number of vertices, and a mixed graph with oriented or non-oriented edges, graph $G=(V, E, c, d)$ comprising of a set $V$ of vertices (e.g. train stations, stops, tariff points and so on), a set $E$ of edges (e.g. interstationary sections $), c(h)$ a permeable capacity of the edge or edge part, $(h)$ is the length of the edge.

In transport networks, as in other systems, the distinguishing level is important. The timetables for rail passenger services are sufficient just when one station is in the graph, represented by a single vertex (from network sense, this is called a node). But for the management needs of rail passenger services, each station is designed for the boarding and disembarking of passengers (flow change on the edge) that are seen as a particular peak [1].

An extension of a conventional line, periodic transport is an integrated periodic timetable (IPTT). In this system are except of periodical repeating of the linear form also monitored the network interconnection and minimising of interchanges times in selected points (transport hubs) where are crossing the individual lines operated for a given period. The aim of this network effect is to minimise the total transferring time of the passenger from point A to point B. This is the most difficult form of operation for transport services, because it demands precision planning and has requirements in terms of boundary conditions. The essential requirements are imposed on the size of the edge periodic time between two nodes, where mutual changes are expected. Substituting the time of the edge can be implemented by a combination of measures related to the infrastructure, setting of the corresponding vehicles, and finally, the connections offered (timetable) [2].

The basis of IPTT consists of the periodic timetable of the superior railway network. Optimal transfer options are given when all trains meet at the same time at a transfer node (usually it is a transfer train station). In this time period, it is necessary to operate the transfer point by additional means of transport. Thus it is possible, with minimum cost, to transport the passengers from all areas to the transfer stations. In an analogous treatment are passenger transported in the opposite direction in a relatively short time. This creates a scheme of connections in the transfer node, the so-called 'transfer spider' [3].

Any such transfer spider has a timeline that represents the period of time for the transfer in the node. This timeline

\footnotetext{
* ' 'Jozef Gasparik, ${ }^{1}$ Vladimir Luptak, ${ }^{2}$ Petr V. Kurenkov, ${ }^{1}$ Pavol Mesko

${ }^{1}$ University of Zilina, Faculty of Operation and Economics of Transport and Communications, University of Zilina, Slovakia

${ }^{2}$ Moscow State Transport University, Institute of Management and Information Technology, Moscow, Russia

E-mail: jozef.gasparik@fpedas.uniza.sk
} 
determines the edge time. The situation depicted in transfer spiders is regularly repeated after every time period.

The connections meet from opposite directions on the line (for trains crossing) because of timetable symmetry at intervals equal to half the time period. Thus, if the transfer node is situated in the time span of an integer multiple of half of the period, the meeting of lines from the opposite direction is just in these nodes.

The time interval between the symmetrical axes of transfer spiders of two adjacent transfer nodes is called edge time. For periods of one hour, the edge times are 30,60, 90 minutes. In the systematised transport network described above, one point to any other point can be done without any major time loss from waiting for connections. This possibility should be given for round-trips back to the starting point, so that the axis of symmetry ends in the transfer spider. Therefore, the time required for the round-trip is equal to an integral multiple of the period. These laws show that the timetable conditions of this kind require contingent journey times between nodes; there is no need to prefer the maximum line speed, because all depends on a system travel time.

\section{Description procurement systems in use today}

With the continuity of the traffic flow, it is necessary to choose two places with the coordinates $\mathrm{x}_{1}$ and $\mathrm{x}_{2}$ on the route of the transport flow. The size of the flowing masses (e.g. number of trains), located at time t, respectively, $t+\Delta t$, between these points is:

$\int_{x_{1}}^{x_{2}} h(x, t) d x$, resp. $\int_{x_{1}}^{x_{2}} h(x, t+\Delta t) d x$

and thus, their difference, indicating a change of this size is:

$D=\int_{x_{1}}^{x_{2}}(h(x, t+\Delta t)-h(x, t) d x$

This difference of $D$ can be expressed in other ways, such as the difference between during the interval $(t, t+\Delta t)$ flowing through point $x_{1}$ and $x_{2}$, and flowing off through point $x_{2}$ :

$$
\begin{aligned}
D & =\int_{t}^{t+\Delta t} q\left(x_{1}, \tau\right) d \tau-\int_{t}^{t+\Delta t} q(x 2, \tau) d \tau= \\
& =\int_{t}^{t+\Delta t}\left[q\left(x_{1}, \tau\right) d \tau-q\left(x_{2}, \tau\right)\right] d \tau
\end{aligned}
$$

From the merit of definite integrals results that at each fixed $\tau$, or $x$ is equally:

$$
\begin{aligned}
& q\left(x_{1}, \tau\right)-q\left(x_{2}, \tau\right)=-\int_{x_{1}}^{x_{2}}\left[\frac{\partial q\left(x_{1}, \tau\right)}{\partial x}\right] d x \\
& h(x, t+\Delta t)-h(x, t)=\int_{t}^{t+\Delta t}\left[\frac{\partial h(x, \tau)}{d \tau}\right] d \tau
\end{aligned}
$$

and thus the difference $D$ can be expressed by a double integral, changing the order of integration:

$D=\int_{x_{1}}^{x_{2}}\left[\int_{t}^{t+\Delta t}\left(\frac{\partial h(x, \tau)}{d \tau}\right) d \tau\right] d x=$

$\int_{t}^{t+\Delta t}\left[\int_{x_{1}}^{x_{2}}\left(\frac{\partial q(x, t)}{\partial x}\right) d x\right] d \tau=$

$\int_{x_{1}}^{x_{2}}\left[\int_{t}^{t+\Delta t}\left(-\frac{\partial q(x, \tau)}{d x}\right) d \tau\right] d x$

Because the first and third integrals have the same limits, and those limits were chosen arbitrarily, also from the integrals equality result integrated functions, and therefore, at any point $x$ and any time $\tau$ must be true:

$$
\begin{aligned}
\frac{\partial h(x, \tau)}{d \tau}= & -\frac{\partial q(x, \tau)}{d x} \Longleftrightarrow \frac{\partial h(x, \tau)}{d \tau}+ \\
& +\frac{\partial q(x, \tau)}{d x}=0
\end{aligned}
$$

This is one of the most important relationships in traffic flow theory. We call it the continuity equation of traffic flow. In accordance with the physical analogy as well transport flow conditions for the rail transportation conditions, the basic state quantities are characterised, which are necessary for the quality evaluation of connections in the transport network. Generally, there is a need to interpret them for the indicators of relevant quality values. Generally, the state quantities are [1]:

\section{- speed}

- intensity $=$ number of units of flow, passing a given point per unit of time

- density $=$ number of flow units per unit distance routes in a given place and a given time

- wave speed $=$ speed of point movement with a given density.

\section{Defining quality indicators for the links evaluation on the transport network}

The proposed methodology aims to comprehensively cover the possibility of achieving any pair of tariff points by passenger trains on a selected rail network in order to assess the quality of the travel opportunities in the area using selected indicators.

The methodology is based on the evaluation of defined criteria for connectivity between the selected tariff points on the network. Based on the methodology, we evaluate a particular connection. It is necessary to determine whether the connection is evaluated during the workday or the weekend. It is also possible to evaluate a selected workday, Saturday, or Sunday. Consequently, we evaluate the summarising indicators for services in terms of particular relations within the examined networks [4]. 
For assessing the connectivity and quality of connections in an examined relation (session), we identify the following factors, some of which are introduced in literature [2 - 6]:

- Number of connections $N_{s}$ during the reporting day, direct connections as well connections with changes (transfers).

- Average waiting time of passenger $W_{i}$. This is the time that the passenger has to wait for a connection to a point of departure, or possibly a transfer point. It is defined as half of the time between the departures of two successive connections.

- Distance route of relation $L_{i}$. This is the travel distance by vehicles creating the connection. This criterion is important to calculate transportation speed and the rate of achievement.

- Type and number of trains creating the connection. This factor reflects the quality of transport services on the connection.

- Transportation time $T_{p}$. Time between the departure from the boarding station on the route and disembarking the train at the destination railway station (tariff point).

- Number of transfers (changing means of transport) $N_{p}$. This is the absolute number of changes of transport vehicles (trains) before reaching the target station.

- Transfer time $T_{w}$. This is the total time that passengers spend waiting for connections at the transfer station (by changing means of transport) when using a particular connection.

- Achieving time $T_{D}$. This is the time from embarking when the travel trip begins, to the arrival of the train at the destination railway station. It is calculated as the sum of the average waiting time and transportation time.

- Transportation speed $V_{P}$. This is given as a proportion of the distance travelled and time of transfer.

- Achieving start-stop speed $V_{D}$. This is given as a proportion of the length of the relation and achieving time [5].
Transportation speed and achieving speed are important evaluation criteria for the quality of a particular connection relation. They are convenient indicators for comparing public transport link connections with individual transport [6].

After processing the connections, an evaluation of a single session is necessary to evaluate the relation between tariff points on the network. For each session averages of criteria for all connections are calculated: the number of transfers, transfer time, the speed of transfer rate and speed of achievement [7]. For an example see Table 1.

\subsection{Comparative analysis of selected indicators for timetable assessment}

Table 2 are processed the start-stop achieving speeds on selected connections and evaluated the average per relation from Bratislava hl.st to selected tariff points. Studied were timetable periods 2013, 2014, 2015 and 2016.

On the ground of the average values we can conclude that the examined start-stop achieving speeds have downward trend in the three periods, but the current timetable 2016 has contrary increasing trend. It shows that the timetable 2016 is in terms of start-stop achieving speeds better quality in general. It is an objective indicator for timetable quality evaluation.

Sample of connection assessment on the $\mathrm{X}-\mathrm{Y}$ relation (workday)

Table 1

\begin{tabular}{|c|c|c|c|c|c|c|c|c|c|c|c|}
\hline 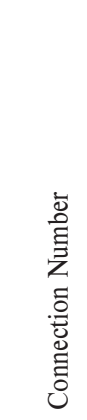 & 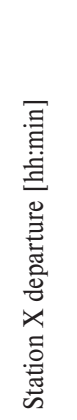 & 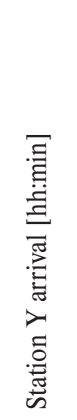 & 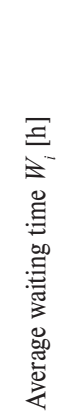 & 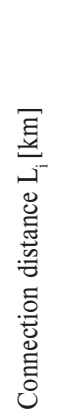 & 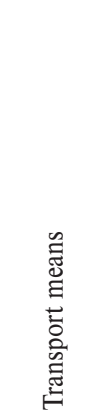 & 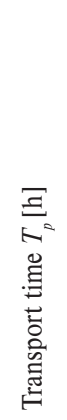 & 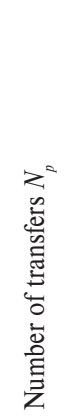 & 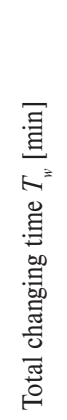 & 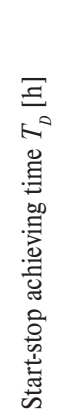 & 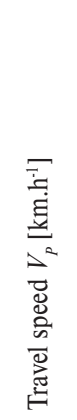 & 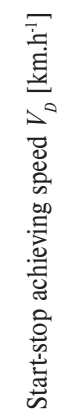 \\
\hline 1 & $6: 53$ & $9: 36$ & 6.25 & 158 & $\mathrm{R}$ & 2.72 & 0 & 0.00 & 8.97 & 58.16 & 17.62 \\
\hline 2 & $8: 03$ & $12: 20$ & 0.58 & 192 & $\mathrm{R}, \mathrm{Os}, \mathrm{Os}$ & 4.28 & 2 & 0.28 & 4.87 & 44.82 & 39.45 \\
\hline 3 & $10: 53$ & $13: 44$ & 1.42 & 158 & $\mathrm{R}$ & 2.85 & 0 & 0.00 & 4.27 & 55.44 & 37.03 \\
\hline $\mathrm{n}$ & $18: 53$ & $21: 35$ & 1.42 & 158 & $\mathrm{R}$ & 2.70 & 0 & 0.00 & 4.12 & 58.52 & 38.38 \\
\hline \multicolumn{7}{|c|}{ Average per connection: } & 0.88 & 0.22 & 4.96 & 53.04 & 38.49 \\
\hline
\end{tabular}

Source: Authors 
Comparison of more timetable periods assessment according to the average start-stop achieving speed indicator

\begin{tabular}{|c|c|c|c|c|c|c|c|}
\hline 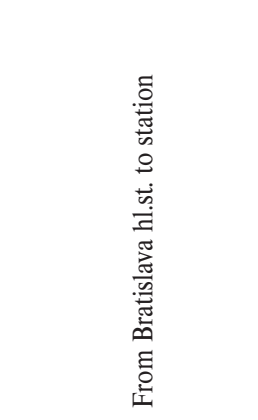 & 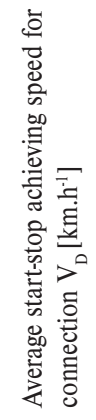 & 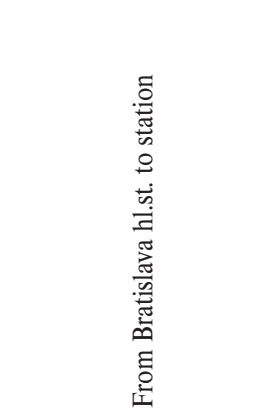 & 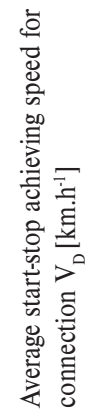 & 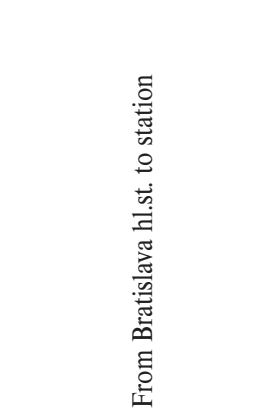 & 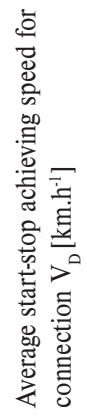 & 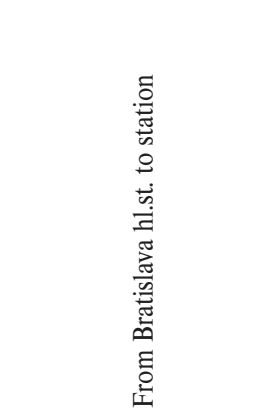 & 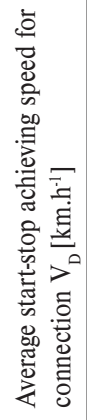 \\
\hline \multicolumn{2}{|l|}{ Timetable 2013} & \multicolumn{2}{|l|}{ Timetable 2014} & \multicolumn{2}{|l|}{ Timetable 2015} & \multicolumn{2}{|l|}{ Timetable 2016} \\
\hline Kosice & 66.62 & Kosice & 66.62 & Turcianske Teplice & 67.17 & Kosice & 65.09 \\
\hline Presov & 65.33 & Poprad & 59.50 & Trencin & 65.21 & Trencin & 64.43 \\
\hline Poprad-Tatry & 64.48 & Cierna n. Tisou & 59.07 & Kuty & 61.47 & Nove Zamky & 62.55 \\
\hline Zilina & 62.92 & Tat. Lomnica & 58.79 & Poprad & 60.01 & Poprad & 62.27 \\
\hline Trencin & 62.39 & Nove Zamky & 58.25 & Nove Zamky & 57.03 & Presov & 61.65 \\
\hline Trebisov & 60.41 & Trencin & 57.25 & Tat. Lomnica & 56.86 & Zilina & 61.35 \\
\hline Cierna n. Tisou & 59.07 & Zilina & 57.19 & Sturovo & 56.66 & Trebisov & 60.46 \\
\hline Nova Zamky & 59.01 & Turcianske Teplice & 57.14 & Piestany & 55.17 & Humenne & 59.86 \\
\hline Gelnica & 58.94 & Sturovo & 56.66 & Sabinov & 54.28 & Kuty & 58.31 \\
\hline Tat. Lomica & 58.79 & Strbske Pleso & 54.24 & Martin & 54.08 & Cierna n. Tisou & 57.29 \\
\hline . & . & . & . & . & . & . & . \\
\hline · & · & · & · & · & . & · & · \\
\hline . & . & . & . & . & . & . & . \\
\hline Kremnica & 36.78 & Banska Stiavnica & 32.81 & Dunajska Streda & 31.74 & Prievidza & 38.18 \\
\hline Zeliezovce & 36.50 & Vranov n. Toplou & 32.49 & Kremnica & 30.97 & Skalite & 37.72 \\
\hline Myjava & 36.16 & Dunajska Streda & 31.67 & Utekac & 30.61 & Kremnica & 37.57 \\
\hline Makov & 34.74 & Kremnica & 30.97 & Vranov n. Toplou & 29.77 & Skalica & 36.08 \\
\hline Dunajska Streda & 33.86 & Utekac & 30.53 & Bardejov & 27.80 & Banska Stiavnica & 34.49 \\
\hline Sahy & 33.31 & Bardejov & 27.61 & Stara Lubovna & 26.03 & Dunajska Streda & 32.05 \\
\hline Banska Stiavnica & 28.84 & Záhorska Ves & 25.33 & Makov & 25.55 & Sahy & 31.61 \\
\hline Zahorska Ves & 23.72 & Makov & 25.18 & Zahorska Ves & 25.33 & Zahorska Ves & 25.21 \\
\hline Zlate Moravce & 18.60 & Zlate Moravce & 19.58 & Zlate Moravce & 18.56 & Zlate Moravce & 18.91 \\
\hline Average per connection & 47.34 & Average per connection & 43.26 & Average per connection & 43.22 & Average per connection & 47.86 \\
\hline
\end{tabular}

Source: Authors

\section{An adequate number of network connections using the Lill's model}

In transport planning, it is possible to encounter situations where it is necessary to determine quantified estimates of the size of traffic flows between two points over a selected period of time (intensity, density), for situations where it is not possible to carry out a direct survey of transport demand. It is also necessary, in some cases, to determine the impact of individual measures of the transport department of the size of its traffic share. This applies particularly to the number of changes in transport, the number of connections or transport distances [8]. For these reasons, empirical models are used for determining of the passenger flow characteristics (Lill's model), which is closely related to the number of available network connection [2, 9 and 10]. 


\subsection{Lill's model}

Lill's model is used to determine the approximate number of connections between two settlement units, where the distance is generally considered between centres. Lill's model has the following form [2]:

$j_{1,2}=\frac{A_{1} \cdot A_{2}}{d^{n}} \cdot K$

where:

$j_{l, 2}$ number of trips between the two cities for a specified time period

$A_{12}$ population (in thousands) at specific locations

$d$ distance places

$K$ index (is depending on the largeness and binding of locations 1 and 2),

$N$ value approaching the value of 2 .

\subsection{Expansion possibilities of the gravity model}

Due to the large variation of optimal values in Lill's gravity model and of actual values, it is essential to modify the current formula for optimal number of connections between two points. This expanded formula shall give more real values as well to be an objective evaluator of quality of transport relations and connections [7 and 10].

The current formula Lill's gravity model considers only the population of origin and destination traffic and point to their remoteness, the objectivity of the evaluation is not satisfactory. The proposed extension of the model under consideration, with a population in transit traffic points within those programs, as well as distance of railway station (stop) from the centre of individual towns and villages of surveyed session. Transit traffic point in this case means any train station, which is considered the loading and disembarking of passengers. These factors may also significantly affect the number of passengers carried and thus the number of optimal connection of the session [11].

The extended model will reflect the fact that the population of individual settlements is directly proportional to the number of transported passengers, but the distance between settlements and access to railway stations (stops) is inversely proportional to this number. This modified model will consider an optimal number of connections in passenger rail transport only, generally in one direction (for both directions the value will be multiplied by two). The proposed formula for the extended Lill's gravity model is [2 and 12]:

$j_{1,2}=\frac{\frac{A_{1} * A_{2}}{d_{1} * d_{2} * l_{1}^{2}}+\frac{A_{2} * A_{3}}{d_{2} * d 3 * l_{2}^{2}}+\cdots+\frac{A_{n-1} * A_{n}}{d_{n-1} * d_{n} * l_{n-1}^{2}}}{n}$ where:

$j_{12} \quad$ optimal number of trips between the two settlements for a specified time period

$A_{l}$ population (current in thousands) at first, starting, point (settlement)

$A_{2}$ population (current in thousands) at first, transit, point (settlement)

$A_{n}$ population (current in thousands) at terminal point (settlement)

$d_{1}$ availability of railway station / stop (the distance from the settlement centre) of starting point [km]

$d$ availability of railway station / stop (the distance from the settlement centre) of first transit point [ $\mathrm{km}]$

$d$ availability of railway station / stop (the distance from the settlement centre) of terminal point [ $\mathrm{km}]$

$l_{l}$ distance between the starting and the first transit point [km]

$l_{2}$ distance between the first and the second transit point [km]

$l_{n-l}$ distance between the last transit and the terminal point [km]

$n$ number of points (stops) within a transport relation, including start and terminal points

$K$ modified original gravity model index.

The formula represents in detail the dependence of quantitative indicator of the quality of transported passengers and the indicators of population, transport distance and accessibility of stations (stops). From its structure it shows that the number of summands in the numerator of the main fraction is dependent on the number of train stops at different stations and stops in the relation. The modified original gravity model index is determined by expert estimation and generally takes the value of $5-25$. It depends on the nature, distance, or even the number of individual settlements on a given relation. In case of major number of stops and the relatively short distances between the transport points the index will acquire lower values. In case of fewer stops and longer distances between these points the index will acquire higher values [7 and 13].

\section{Conclusion}

The proposed methodology is used for the possibility of achieving any pair of tariff points in a selected railway network comprehensively. It not only offers an evaluation of the connectivity of a particular relation, but also objectively assesses the availability of connections between two selected tariff points, based on quality indicators such as average number of transfers, average waiting time, average transportation speed, and average achieving speed. This 
enables us to evaluate the quality of the travel opportunities in this area by using selected indicators. Subsequently, using multiple criteria analysis allows us to evaluate the degree of customer satisfaction with selected quality attributes based on their importance. Ultimately, it is possible to examine the statistical dependence of the number of transported rail passengers by examining the quality connection of the network [11, 13 and 14].

The proposal will contribute to the creation of a competitive transport system that efficiently uses system resources. Such is the plan of a Single European Transport Area within the purview of the white paper, 'Roadmap to a Single European Transport Area-Towards a competitive and resource efficient transport system'. This aims for the attainment of an efficient and integrated system of mobility. The importance of the quality, accessibility, and reliability of transport services in the coming years may be even more important [15 and 16].
Another aim of the article is to outline the methodology for determining the required number of transport links between settlement units in passenger traffic. In terms of passengers, it must assess the availability of opportunities to travel between selected points on the transport network. Offering transportation from point A to point B in principle affects transportation time, the number of connections and the number of travel opportunities. On connections and the transfer, connections are thus influenced by a number of factors in transport planning, which is the basis for the empirical model [13].

\section{Acknowledgements}

The paper is supported by the VEGA Agency under Project $1 / 0095 / 16$, 'Assessment of the quality of connections on the transport network as a tool to enhance the competitiveness of public passenger transport system'.

\section{References}

[1] CERNA, A., CERNY. J.: Managerial Decisions about Transport Systems (in Czech), University of Pardubice, 2014,230 p., ISBN 978-80-7395-849-7.

[2] DRDLA, P.: Passenger Traffic Regional and National Importance (in Czech), University of Pardubice, No. 1., 2014,412 p., ISBN 978-80-7395-787-2

[3] LUPTAK, V., GABOROVA, V., ZITRICKY. V.: The Application of Empirical Models in Transport Planning in the Slovak Republic (in Slovak), Zeleznicna doprava a logistika, 2015, p. 10-13. ISSN 1336-7943. Online at:

https://fpedas.utc.sk/zdal/images/zdal/archiv/zdal_2015_02.pdf

[4] POLIAK, M., KRIZANOVA, A., SEMANOVA, S., GAJANOVA, L.: The Influence of Contract form Choice of the Transport Services Ensuring on Performance Contracting Entity Requirement. Transport Problems = Problemy Transportu: Intern. Scientific J., vol. 9, No. 4, 2014, pp. 153-161, ISSN 1896-0596

[5] STOPKA, O., SIMKOVA, I., KONECNY, V.: The Quality of Service in the Public Transport and Shipping Industry. 2015. Nase More, University of Dubrovnik, vol. 62, Special Issue, 126-130. ISSN 0469-6255

[6] GASPARIK, J.; SIROKY, J.; PECENY, L.; HALAS, M.: Methodology for Assessing the Quality of Rail Connections on the Network. Communications - Scientific Letters of the University of Zilina, vol. 16, No. 2, 2014, 25-30. ISSN 1335-4205

[7] ZITRICKY, V., GASPARIK, J., PECENY, L.: The Methodology of Rating Quality Standards in the Regional Passenger Transport. Transport Problems = Problemy Transportu: International Scientific J., sp. Edition, vol. 10, 2015, pp. 59-72

[8] KENDRA, M.; MASEK, J.; PONICKY, J. et al: Proposal of Methodology for Calculating the Quantity of Validation Machines in Railway Transport, Conference: $6^{\text {th }}$ Transport Research Arena (TRA), Warsaw: Book Series: Transportation Research vol. 14, 1977-1986.

[9] ALDIAN, A., TAYLOR, M. A. P.: Fuzzy Multicriteria Analysis for Inter-city Travel Demand Modelling. J.of the Eastern Asia Society for Transportation Studies, vol. 5, 2003, 1294-1307

[10] HADAS, Y., CEDER, A.: Public Transit Network Connectivity: Spatial-based Performance Indicators. Transportation Research Record: J. of the Transportation Research Board, 2143, 2010, 1-8

[11] YEDLA, S., SHRESTHA, M.: Multi-criteria Approach for the Selection of Alternative Options for Environmentally Sustainable Transport System in Delhi. Transportation Research Part A, vol. 37, No. 8, 2003, 717-729, ISSN: 0965-8564

[12] LUPTAK, V., GASPARIK, J., PECENY, L.: Methodology for Assessing the Quality of Rail Connections on the Network. Proc. of conference Transcom 2015, University of Zilina, 81-86, ISBN 978-80-554-1043-2

[13] MISHRA, S., WELCH, T.F., JHA, M.K.: Performance Indicators for Public Transit Connectivity in Multi-Modal Transportation Networks. Transportation Research Part A: Policy and Practice, 46, 2012, 1066-1085 
[14] SCHULZ, A.: Integrated Periodic Timetable in Germany (in German). Eisenbahn-Revue International, No. 9-10, 1994, 277-284

[15] STOPKA, O., PONICKY, J., CHOVANCOVA, M., ZITRICKY, V.: Draft Method for Determining the Number of Checking Devices Utilized within the Regional Passenger Transport. Nase More: J. of Marine Science, vol. 63, No. 3, 200-203. ISSN 0469-6255

[16] HORNAK, M., PSENKA, T., KRIZAN, F.: The Competitiveness of the Long-distance Public Transportation System in Slovakia. Moravian Geographical Reports, 21, 4, 2013, 64-75, ISSN 1210-8812. 